oxidant, nordehydroguaiaretic acid, reduced the amount of oxidation in butter during eight months of storage, but without improving the grade of butter. Of twenty overseas strains of streptococci examined, none was suitable for use as a cheese-starter in New Zealand. The Woollen Mills' Research Association made comparative tests with six worsted oils and also found that 'Lissapol $N$ ' in scouring removed the mineral oils satisfactorily. It was also found that 0.01 per cent of copper was the maximum amount that could be tolerated on the wool in dyeing, and even this amount noticeably affected weak dyeings of sensitive dyes.

\section{QUALITY CONTROL OF LINOLEUM}

$\mathrm{O}^{\mathrm{N}}$ January 31 the Linoleum Research Council, which has only been in existence for not quite three years, held its second symposium at the Grosvenor Hotel, London. The subject on this occasion was "Quality Control" as applied to linoleum, and not only was the industry itself well represented by the gathering of its technical men but also a number of visitors from other related industries were present. The meeting was opened by Dr. K. Turner, chairman of the executive committee, who said that this meeting was a direct result of the first symposium, entitled "The Rheology of Unmatured Linoleum", which had been held in the same place two years ago and which had been sufficiently successful to merit making these meetings a regular affair. $\mathrm{He}$ then handed the meeting over to the superintendent of research, Dr. S. R. W. Martin.

Five papers were presented, and as preprints had been circulated well in advance it was possible to devote most of the time of the meeting to a discussion, which was extremely stimulating and constructive. The first paper, by Mr. F. T. Walker (Messrs. Michael Nairn and Co.), was entitled "Dimensional Changes of Linoleum with Varying Humidity", and outlined the effect of water absorption on the cubical expansion of linoleum at normal temperatures. It was shown that the expansion of the linoleum is directly related to the amount of water absorbed. The effect contributed by the various ingredients of linoleum has been measured, and the fibrous fillers-cork or woodflour-have been shown to be almost entirely responsible. Various physical and mechanical factors which can influence expansion due to moisture absorption were discussed, and the superficial anisotropy of the linoleum sheet resulting from calendering demonstrated.

"The Indentation Machine as an Indication of the End Part in the Process of Maturing Linoleum" was discussed by C. W. Falkner (Linoleum Manufacturing Co., Staines) as an introduction to the study of the whole subject of mechanical testing as an aid to accuracy in judging the process of maturing which forms the final stage in the manufacture of linoleum, and a comparison was made between the indentation test and chemical tests, and new tests in respect of quite new and novel instruments. A more precise description of results obtained by the use of such a new testing device was discussed by $P$. J. Humphris (Linoleum Manufacturing Co.) in a paper entitled "The Rigidity Modulus of Linoleum". A large-scale rigidity machine was described, and attempts have been made to correlate results obtained from this machine with maturing times. There are clear indications that the modulus of rigidity in the case of linoleum is a sensitive property of some structural significance.

An alternative method of assessing the maturing stage of a linoleum was described by Messrs. J. C. Lawson, T. MeQuillen and G. D. Rack (Jas. Williamson and Son, Ltd.) in a paper entitled "Some Experi. ments on the Application of Resilience Testing to Linoleum". Various common methods of measuring resilience of similar materials were discussed, and it was shown that a bouncing-ball technique and also a wheel-rebound test have given valuable results which may be a guide to the correct end of a maturing process.

An interesting paper, which was possibly outside the narrow subject of the symposium but neverthe. less of interest to all present, was given by Dr. F. C. Harper (Building Research Station) on "The Measurement of Slipperiness of Floor Finishes". This described methods which have been used by various investigators for measuring slipperiness and showed how the problem can be simplified if more information is available about the mechanics of walking.

The meeting was concluded with a general summing up by Mr. A. G. Ward (director, British Glue and Gelatine Research Association). Dr. Martin thanked the company and suggested that, by the organization of such meetings where members of the industry can meet together and exchange information of material benefit, the Linoleum Research Council is amply fulfilling one of its functions by acting as a scientific centre for the industry.

\section{PRODUCTIVITY IN THE PACKET FOODS INDUSTRY}

\section{REPORT OF THE ANGLO-AMERICAN COUNCIL ON PRODUCTIVITY}

HE findings and recommendations of the productivity team representing the British packet foods industry that visited the United States last year are of interest to a wider field than those specifically concerned with food and its packaging. The recently published report of the team* does not endeavour to tell the British food industry how it should run its business, nor does it suggest that everything done in the United States is necessarily better than in Great Britain, the general conclusion appearing to be that, if in Britain there were the same unlimited supplies of materials, there would indeed be little difference in efficiency of either the foodstuffs prepared or in the quality of the packaging. Indeed, in this latter respect it seems that many of the undoubtedly superior packages and packaging methods used in the United States result from the ready availability of materials as well as the greater development of self-service stores which have called for more attractive packs in order to tempt purchasers.

Many interesting facts are presented in the report. One learns that food and agriculture in the United States is a "25 per cent industry"--one-fourth of the American income is spent on food, and the industry employs one-fourth of American workers. In the

* Productivity Team Report : Packet Foods. Report of a Visit to the U.S.A. in 1951 of a Productivity Team representing the British Packet Foods Industry. Pp. xil $+71+9$ plates. Sondon and New York: Anglo-American Council on Productivity, 1951.) 48. $6 d$. 